\title{
Characterizing the variation of small strain shear modulus for silt and sand during hydraulic hysteresis
}

\author{
Ali Khosravi ${ }^{1, a}$, Mehrzad Rahimi ${ }^{2}$, Parisa Shahbazan ${ }^{2}$, Ali Pak $^{3}$, and Amin Gheibi ${ }^{2}$ \\ ${ }^{1}$ Assistant Professor, School of Civil Engineering, Sharif University of Technology, Tehran, Iran \\ 2 Graduate Student, School of Civil Engineering, Sharif University of Technology, Tehran, Iran \\ ${ }^{3}$ Professor, School of Civil Engineering, Sharif University of Technology, Tehran, Iran
}

\begin{abstract}
Experimental studies have indicated that the small strain shear modulus, $G_{\max }$, of unsaturated silt and clay has a greater amount during imbibition than during drainage, when presented as a function of matric suction. However, due to material properties and inter-particle forces, different behavior is expected in the case of sand. Although considerable research has been devoted in recent years to characterize the behaviour of $G_{\max }$ of sand during drainage, rather less attention has been paid to the effect of hydraulic hysteresis on $G_{\max }$ and its variations during imbibition. In the study presented herein, an effort has been made to compare the $G_{\max }$ behavior of specimens of silt and sand during hydraulic hysteresis. In this regard, a series of bender element tests were carried out in a modified triaxial test device with suction-saturation control to evaluate the impact of hydraulic hysteresis on $G_{\max }$ for specimens of silt and sand. Trends between the $G_{\max }$ and matric suction for unsaturated sand were found to be different from those for silty specimens. The variations in $G_{\max }$ showed an up and down trend in both drainage and imbibition paths for sandy specimens, where plotted as a function of matric suction. Results also indicated smaller magnitudes of $G_{\max }$ upon imbibition than those during drainage; a behavior which is believed to be attributed to variations in suction stress with matric suction. In silty specimens, a stiffer response was measured during imbibition which was hypothesized to be due to drainage-induced hardening experienced by the specimens that was not fully recovered during imbibition.
\end{abstract}

\section{Introduction}

The knowledge of small strain shear modulus, $G_{\max }$, in unsaturated condition is of particular interest to properly understand the seismic response of geotechnical systems. A significant body of studies have been developed on the measurement of $G_{\max }$ and its relationship with matric suction and mean net stress for unsaturated silt and clay. Former studies showed the importance of concurrent consideration of degree of saturation, $S_{r}$, and matric suction, $\psi$, in characterizing the behavior of $G_{\max }$ for silt and clay during drainage and imbibition [1-4]. Results of previous studies indicated that variations in $G_{\max }$ during drainage had a non-linear increasing trend with matric suction with greater values upon imbibition. This behavior was postulated to be due to plastic hardening the specimens experienced during drainage as a result of changes in degree of saturation and specimen volume.

In contrast to fine grained soils in which a clear and specified trend for $G_{\max }$ with respect to degree of saturation was reported, the $G_{\max }$ of sands was observed to behave differently during drainage with no unique trend between $G_{\max }$ and degree of saturation or matric suction [5-9]. Furthermore, the variations in $G_{\max }$ during imbibition for sand has not been fully investigated.
In the work presented herein, an effort has been made to gain a better understanding of the behavior of $G_{\max }$ during drainage and imbibition for silty and sandy soils. In this regard, a series of bender element tests were carried out in a modified triaxial apparatus with suctionsaturation control to measure variations in $G_{\max }$ under different hydro-mechanical loadings. The modified test setup allowed precise control over matric suction in magnitudes as low as $0.1 \mathrm{kPa}$ corresponding to $10 \mathrm{~mm}$ of suction head. In this setup, the degree of saturation of the specimens during hydro-mechanical loading was obtained through measurements of changes in water level in a burette connected to the bottom of the specimen, while the specimen volume change was measured using a modified Digital Image Processing (DIP) technique.

\section{Tested material and specimen preparation}

Bender element tests were carried out on two different types of soils: Bonny silt and silica sand. Bonny silt was obtained from borrow materials of the Bonny dam near the Colorado-Kansas border and is described as ML in accordance with the Unified Soil Classification System, USCS, (ASTM D 2488-00). The silica sand is a poorly

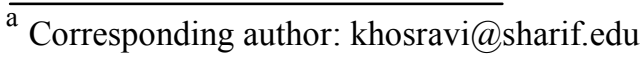


graded fine sand with sub-rounded to rounded particles. Typical properties of these two soils are summarized in Table 1.

Table 1. Geotechnical properties of tested soils.

\begin{tabular}{ccccc}
\hline \hline \multicolumn{2}{c}{ Bonny silt } & & & \multicolumn{2}{c}{ Silica sand } \\
\cline { 1 - 2 } \cline { 5 - 6 } Activity $(\%)$ & 29 & & Mineral & $99 \% \mathrm{SiO}_{2}$ \\
$\gamma_{\text {dmax }}\left(\mathrm{kN} / \mathrm{m}^{3}\right)$ & 16.3 & & $\mathrm{G}_{\mathrm{s}}$ & 2.65 \\
$\mathrm{w}_{\text {opt }}(\%)$ & 13.6 & & $\mathrm{e}_{\max }$ & 0.9 \\
$\mathrm{D}_{50}(\mathrm{~mm})$ & 0.039 & & $\mathrm{e}_{\min }$ & 0.62 \\
$\mathrm{D}_{10}(\mathrm{~mm})$ & 0.0013 & & $\mathrm{D}_{50}(\mathrm{~mm})$ & 0.19 \\
Clay fraction $(\%)$ & 14 & & $\mathrm{C}_{\mathrm{u}}$ & 1.29 \\
LL, PL, PI & $25,21,4$ & & $\mathrm{D}_{\mathrm{r}}(\%)$ & 67 \\
$\mathrm{e}_{\text {Initial }}$ & 0.85 & & $\mathrm{e}_{\text {Initial }}$ & 0.71 \\
\hline \hline
\end{tabular}

Cylindrical silty and sandy specimens with $60 \mathrm{~mm}$ diameter and $120 \mathrm{~mm}$ height were prepared using the static compaction and aerial pluviation (sand raining) techniques, respectively. To prepare the silty specimens, the de-aired water was added and uniformly mixed with a desired amount of dried soil. Thereafter, the soil was statically compacted in 6 layers in a cylindrical mold to reach an initial void radio, e, of 0.85 . After compaction, the specimen was removed from the mold and immediately placed in the triaxial testing apparatus. For the sandy specimens, specific amount of oven-dried sand was pluviated from a guide tube through a series of holes into a membrane expanded over a split mold, placed on the pedestal of the testing setup. The height of the sand free-fall and its deposition intensity were then controlled to obtain specimens of $e=0.71$.

\section{Experimental setup and testing procedure}

A bender element test setup with suction-saturation control was developed to measure variations in $G_{\max }$ of specimens of silt and sand along different paths of drainage and imbibition under different levels of mean net stress. A schematic layout of the testing system is presented in Figure 1. The experimental approach includes the use of bender elements for $G_{\max }$ measurements, the axis translation technique [10] to apply and control the desired matric suction, Digital Image Processing (DIP) technique for specimen's volume change measurement during each step of loading, and a high pressure hydraulic pump for high mean net stress testing for silt.

The shear wave velocity and the corresponding small strain shear modulus were measured using a pair of bender elements, designed and built at Sharif University of Technology, one as a source and the other as a receiver, installed inside the bottom platen and the top cap, respectively. A signal generator, Model TTI, TGA1241 , was used to produce a sinusoidal pulse input signal to the transmitting bender element at the bottom, and a two-channel digital oscilloscope, Pico ADC-212, high speed analogue to digital converter was used to record the signals from both the transmitting and receiving elements. An amplifier was used to amplify the voltage supplied to the transmitting bender element and enhance the response of the bender element soil system.

In this setup, the axis translation technique was used to separately control the air and water pressures, and the corresponding suction value in the specimen during the tests. Water that flows out of/into the setup in response to the applied suction and mechanical load was measured using visual observation of water levels in graduated burettes connected to the water drainage lines from the specimen and confining cell. The Digital Image Processing, DIP, technique was used to measure the volume change of the soil specimens directly. In this technique, a digital camera was placed precisely at the horizontal direction, where its shooting direction perfectly captures any possible change through the height of the specimens. To control the temperature of the testing room, all tests were performed in an isolated humidity and temperature controlled room which was constructed in the advanced soil testing lab at Sharif University of Technology for unsaturated testing.

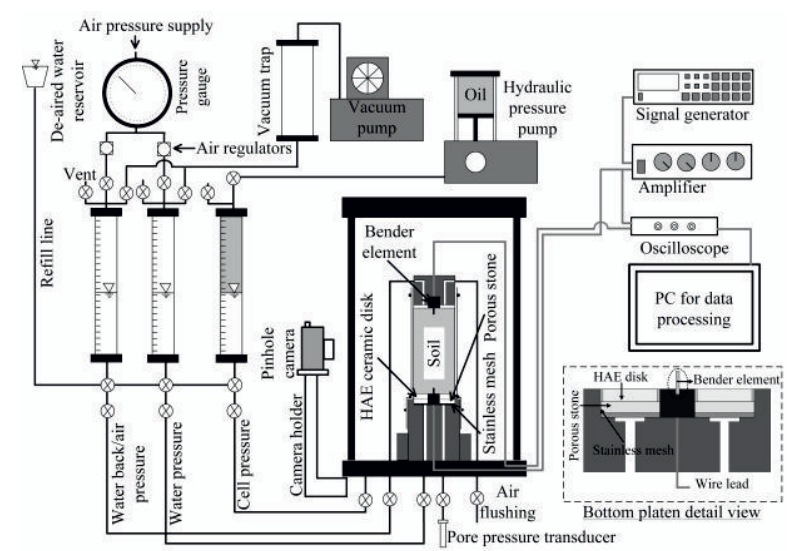

Figure 1. Schematic of the modified triaxial test device equipped with bender elements

After placing the soil specimens within the triaxial setup, the saturation process was initiated using the backpressure technique under $40 \mathrm{kPa}$ net stress for silty specimens and applying vacuum to the top of the sandy specimens following ASTM D 6836-02. When the specimens were saturated, they were imposed to the desired confining pressure and the first step of the bender element test was performed to measure the value of $G_{\max }$ corresponding to the saturated condition. After the specimens were saturated, the desired suction was introduced at the boundaries of the specimens. The desired level of suction in silty specimens was imposed by decreasing the water pressure at the bottom while keeping the air pressure constant at the top. However, in the case of sandy specimens, the matric suction application was performed by elevating the magnitude of air pressure at the top and keeping the water pressure constant through the rest of the test. For the sandy specimens, simultaneous and equal changes in applied confining pressure were made to hold the mean net stress $\left(p_{n}=p-u_{a}\right)$ constant for each incremental change in matric suction. Depending on the level of suction and the soil type, each equalization stage needed 2 to 15 days to be completed. After reaching hydraulic equilibrium, the bender element test was conducted to measure shear 
wave velocity and hence $G_{\max }$ related to each step of unsaturation process. After defining the drainage path of the SWRC and the corresponding $G_{\max }$ values, the decrements of matric suction were applied to the specimens in order to define the trends of $S_{r}$ and $G_{\max }$ during imbibition.

\section{Results}

The SWRCs obtained from tests on silty and sandy specimens under different levels of mean net stress are shown in Figures 2 and 3, respectively. The SWRCs denote initial drainage from a saturated condition up to a desired matric suction of $110 \mathrm{kPa}$ for silt and $15 \mathrm{kPa}$ for sand. As shown in these figures, there is a remarkable difference between the SWRCs subjected to different levels of mean net stress in both types of soils, indicating that the mean net stress and the type of material may have a great effect on the water retention ability of soils. As presented, the mean net stress increase led to an increase in the ability of soil to retain water, resulting in the SWRCs shifting to the right. This behavior can be attributed to rearrangement of soil particles or specimen's volume change due to mean net stress increase. Similar observations were also reported by [1, 2] for silty specimens.

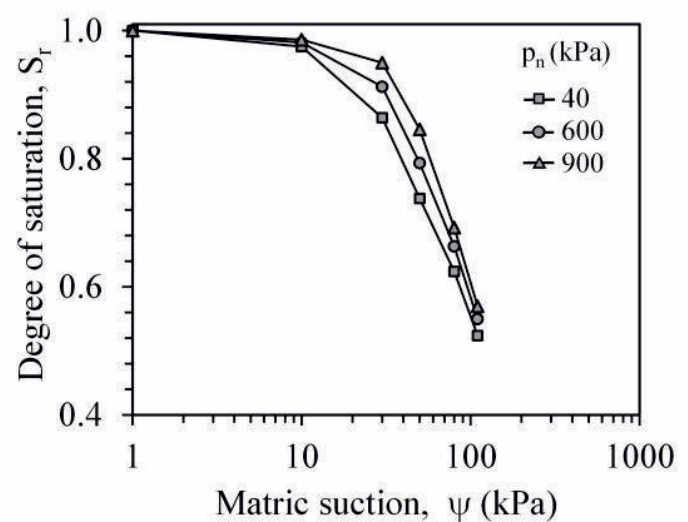

Figure 2. The SWRCs of Bonny silt specimens under different mean net stresses

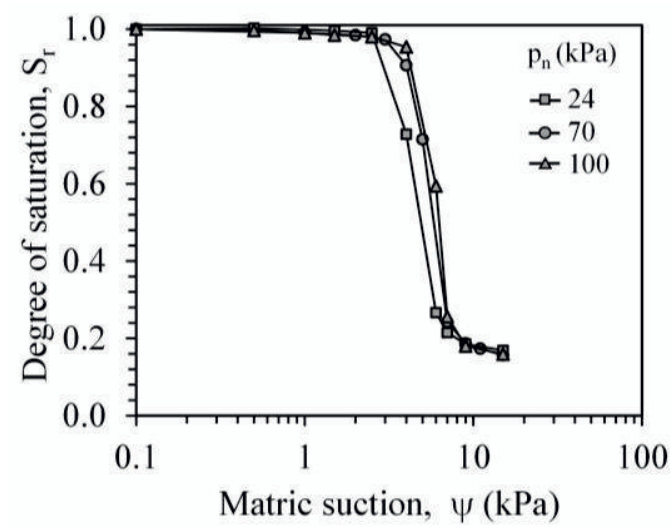

Figure 3. The SWRCs of silica sand specimens under different mean net stresses

The results of six bender element tests carried out on specimens of silt and sand during hydraulic hysteresis are presented in Figures 4 and 5, respectively. As in the case of sandy specimens a narrower range of matric suction was applied, the curves for sandy specimens were plotted in a natural scale, while those of silty specimens were presented in a logarithmic scale. As shown in these figures, the mean net stress has a pronounced effect on $G_{\max }$ values with greater values of $G_{\max }$ at higher net stresses. Moreover, the $G_{\max }$ of silts and sands were observed to behave differently during hydraulic hysteresis. Variations of $G_{\max }$ of silt along the drainage path showed an increasing trend when plotted as a function of matric suction, while an up and down trend for $G_{\max }$ was observed in the case of sandy specimens.

The results of tests on silty specimens shown in Figure 4 indicated two distinct zones for the variation of $G_{\max }$ along the drainage path of the SWRC. For the range of suction below the air entry value, negligible changes in degree of saturation of the specimens with suction increase were resulted in slight increase in $G_{\max }$ during drainage. For suctions ranging from air entry suction to a matric suction of $110 \mathrm{kPa}$, a greater increase in $G_{\max }$ was measured during drainage, although a limiting value was not expected for silty specimens because of the relatively high degree of saturation.

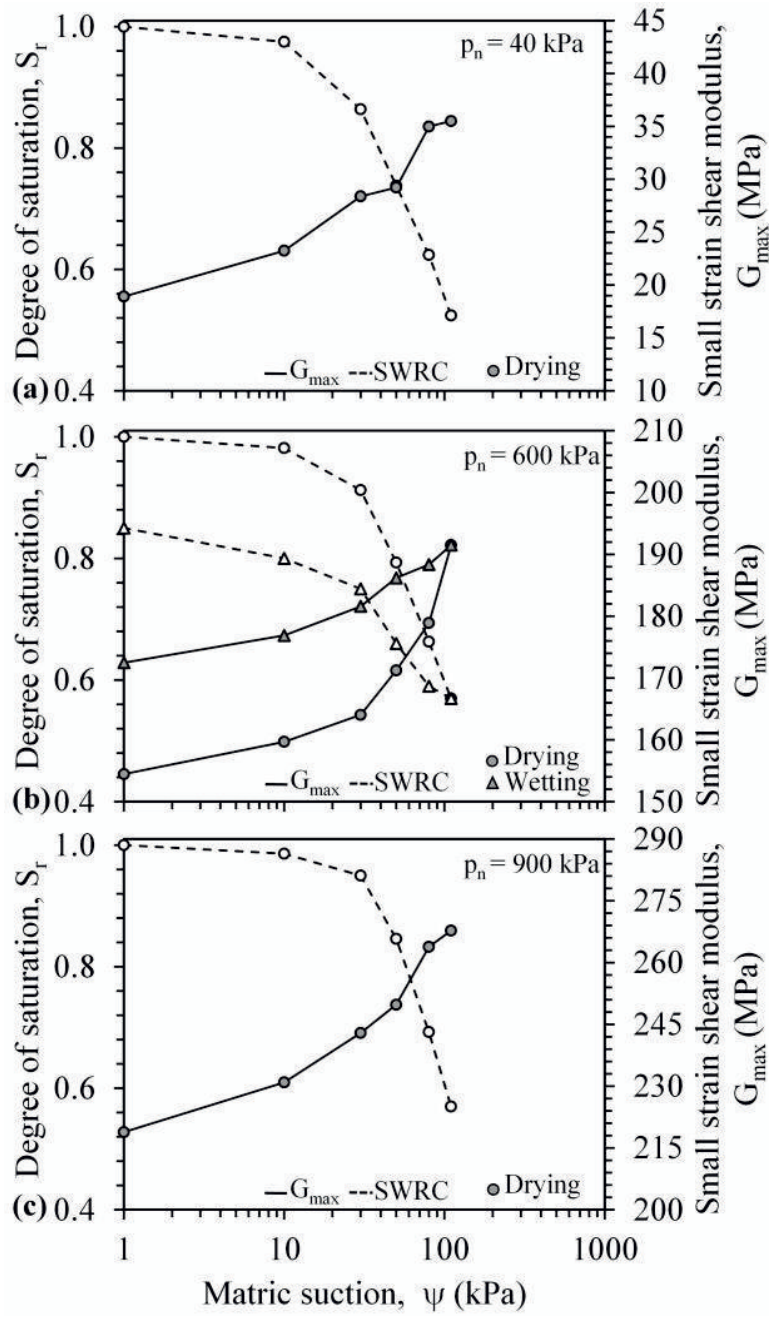

Figure 4. Results of $G_{\max }$ together with corresponding SWRC for Bonny silt specimens at various values of mean net stress: (a) $P_{n}=40 \mathrm{kPa}$; (b) $P_{n}=600 \mathrm{kPa}$; (c) $P_{n}=900 \mathrm{kPa}$ 
In the case of sand, as presented in Figure 5, the measured $G_{\max }-\psi$ trends showed an up-and-down characteristic for suctions ranging from zero to the value corresponding to the residual condition. For the range of suction from zero to the air entry value, matric suction increase led to a relatively linear increase in $G_{\max }$. However, for suctions beyond the air entry value, depending on the magnitude of applied mechanical load, the $G_{\max }$ trends showed a little difference in behavior. At lower mean net stresses of $24 \mathrm{kPa}$ and $70 \mathrm{kPa}, G_{\max }$ initially increased to a peak value at a suction value of 4 $\mathrm{kPa}$ (a value beyond the air entry suction), after which a sudden drop in its magnitude was observed with suction increase. For the specimen under the mean net stress of $100 \mathrm{kPa}$, after reaching a maximum value at the air entry suction, the $G_{\max }-\psi$ curve followed a decreasing path toward a minimum value at residual suction. For suctions greater than the residual value, regardless of the magnitude of applied mean net stress, the rate of changes in degree of saturation was negligible and $G_{\max }$ experienced a slight decrease in magnitude with suction increase.

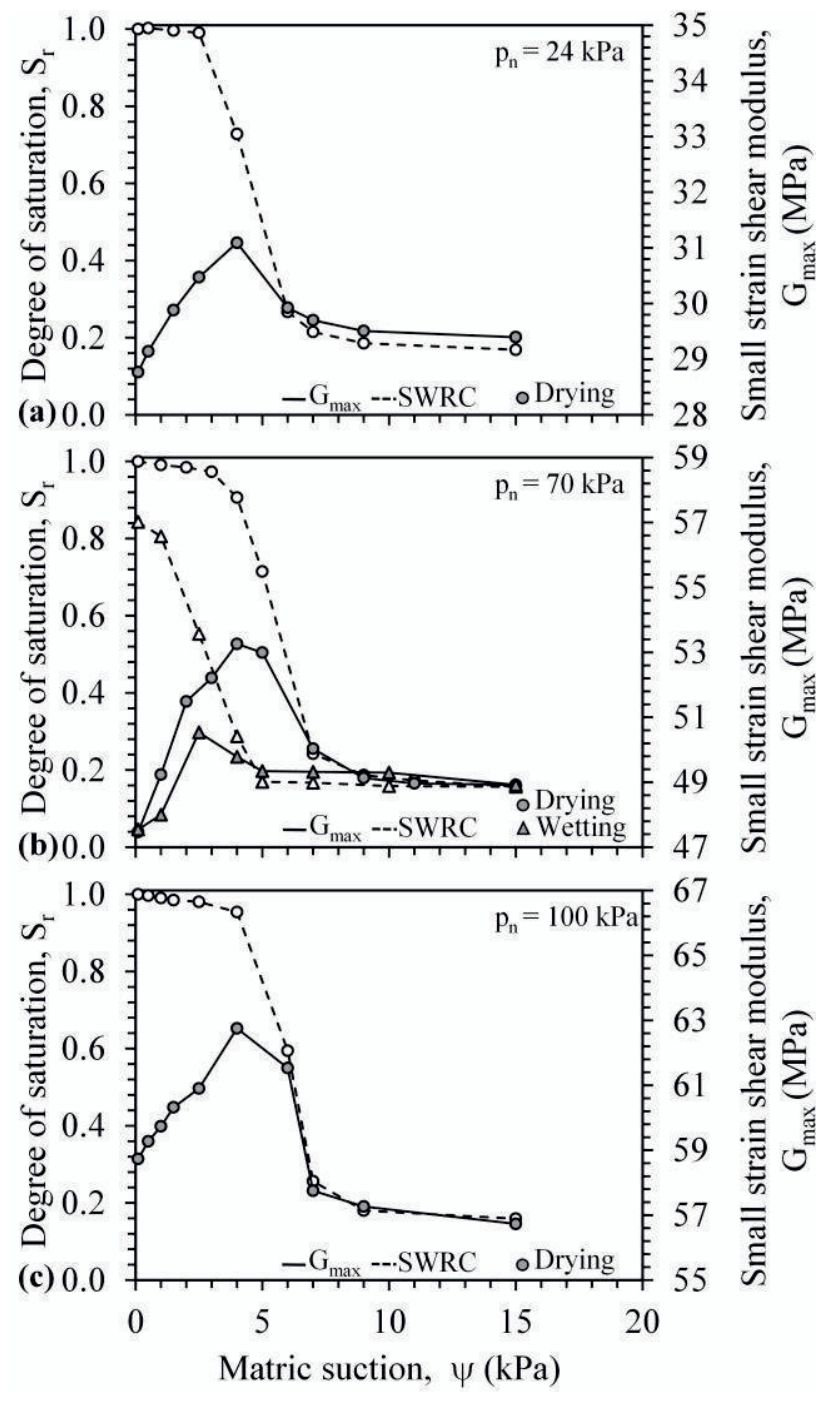

Figure 5. Results of $G_{\max }$ together with corresponding SWRC for silica sand specimens at various values of mean net stress: (a) $P_{n}=24 \mathrm{kPa}$; (b) $P_{n}=70 \mathrm{kPa}$; (c) $P_{n}=100 \mathrm{kPa}$
To investigate the effect of hydraulic hysteresis on the $G_{\max }$ measurements of silt and sand, the specimens under the mean net stresses of $600 \mathrm{kPa}$ (for silt) and $70 \mathrm{kPa}$ (for sand) were subjected to subsequent imbibition after drainage. In this regard, after an initial drainage, the specimens were imbibed thorough the imbibition paths of the SWRCs from an initial matric suction of $110 \mathrm{kPa}$ (for silt) and $15 \mathrm{kPa}$ (for sand) down to the zero matric suction. The results of these tests are presented in Figures 4(b) and 5(b) for silty and sandy specimens, respectively. As shown in these figures, for both tested materials, similar to the SWRC curves, there was a hysteretic behavior in $G_{\max }$ during imbibition. However, trends for $G_{\max }$ along the imbibition path were observed to be different for silty and sandy specimens.

Upon imbibition, $G_{\max }$ of the silty specimen experienced a reduction in magnitude with decreasing suction, a trend similar to that during drainage. The value of $G_{\max }$ was observed to have a slight decrease in magnitude with suction decrease when above or near the water entry. With further decrease in suction, significant amount of water was absorbed by the specimen, leading to a greater decrease in $G_{\max }$ during imbibition. The rate of changes in $G_{\max }$ during imbibition was observed to be smaller than that during drainage, resulting in the measurement of higher values of $G_{\max }$. For the sandy specimen, similar to the drainage path, an up-and-down trend was noted for $G_{\max }$ along the imbibition path. However, for the same magnitudes of equilibrium suction, the values of $G_{\max }$ for sand during imbibition were consistently smaller than those during drainage.

\section{Analysis}

\subsection{Characterization of the $G_{\max }$ behavior for silty specimens}

The hysteretic behavior of $G_{\max }$ with matric suction during cycles of drainage and imbibition for silty soils has been postulated to be as a result of drainage-induced hardening which was not fully recovered during imbibition. Accordingly, the values of $G_{\max }$ along the imbibition path has been observed to be higher than those measured during drainage. In recent studies on $G_{\max }$ of unsaturated silt, the hardening effects associated with changes in degree of saturation or volume change were considered through the term mean preconsolidation stress, $p_{c}{ }^{\prime}$, which can be described using an expression proposed by [2] as follows:

$\frac{p_{c}{ }^{\prime}}{p_{c 0}{ }^{\prime}}=\exp \left[\frac{\Delta e^{p}}{\lambda-\kappa}+b\left(S_{e 0}-S_{e}\right)\right]$

where $p_{c 0}{ }^{\prime}$ is the mean preconsolidation stress at saturation, $\Delta e^{p}$ is a plastic change in void ratio, $\lambda$ and $\kappa$ are the slopes of the virgin compression and elastic rebound parts of the isotropic compression curve, $b$ is a hardening parameter which controls the rate of change in $p_{c}{ }^{\prime}$ with changes in $S_{e}$, and $d S_{e}$ is variations in the effective saturation. $S_{e}$ is defined as follows: 
$S_{e}=\frac{S_{r}-S_{r, \text { res }}}{1-S_{r, \text { res }}}$

where $S_{r}$ is the current degree of saturation, and $\mathrm{S}_{\mathrm{r}, \mathrm{res}}$ is the value of $S_{r}$ in residual condition. A comparison of the trends in $p_{c}{ }^{\prime}$ with the values of $G_{\max }$ measured in the bender element tests during hydraulic hysteresis is presented in Figure 6. In this figure, the values of mean preconsolidation stress were obtained from Eq. 1 using a $b$ value of 2.15 , a $S_{r, \text { res }}$ value of 0.05 , a $p^{\prime}{ }_{c 0}$ of $180 \mathrm{kPa}$ at saturated condition, and zero $\Delta e^{p}$. To obtain the $b$ value, a series of isotropic compression tests were conducted on specimens with the same initial conditions under different levels of matric suction. For the range of suctions used in this study, the specimens were observed to experience relatively little volume change during hydraulic hysteresis.

As presented in this figure, similar to $G_{\max }$ measurements, the predicted drainage and imbibition mean preconsolidation stresses are in a continuous form nonlinear curve when plotted in terms of matric suction, with a smooth transition at the air entry suction. Results also indicated higher values of $p_{c}{ }^{\prime}$ during imbibition than those during drainage, a behavior similar to that noted for $G_{\max }$.

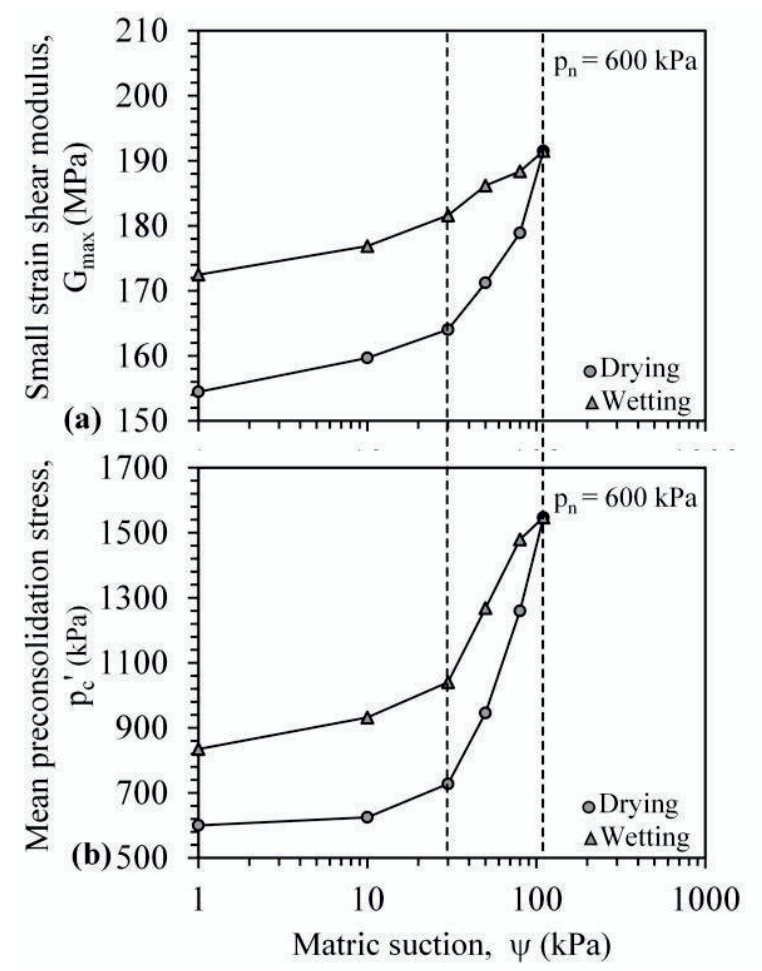

Figure 6. Hysteretic behavior during drainage and imbibition for Bonny silt specimens at mean net stress of $600 \mathrm{kPa}$ : (a) $G_{\text {max }}$; (b) $p_{c}{ }^{\prime}$ (LC yield curve)

\subsection{Characterization of the $G_{\max }$ behavior for sandy specimens}

While the $G_{\max }$ measurements of the silty specimens showed a strong correlation to the mean preconsolidation stress, there are still some difficulties in interpreting trends for $G_{\max }$ of unsaturated sand during hydraulic hysteresis. Based on the results of previous work, the small strain shear modulus for an unsaturated sand is greatly dependent on the effective stress $[6,11,12]$. While the well-known effective stress-dependency of $G_{\max }$, correlations between the small strain shear modulus and effective stress are not well understood. In this study, an attempt was made to define relationships between $G_{\max }$ and effective stress using the concept of suction stress introduced by [13]. The suction stress is a stress variable that incorporates the effect of different inter-particle stresses arising from chemical cementation, van der Waals attraction, capillarity, and double layer repulsion into the effective stress definition for unsaturated soils [13-15]. The suction stress can be easily defined from shear/tensile strength tests data or using a closed-form mechanical expression proposed by [16] as follows:

$p_{s}=\psi \times\left[\frac{1}{1+(\alpha \times \psi)^{n}}\right]^{1-\frac{1}{n}}$

where $p_{s}$ is the suction stress, and $\alpha$ and $n$ are van Genuchten SWRC model parameters.

The values of $G_{\max }$ obtained from the bender element tests are presented in Figure 7(a) and Figure 7(b) show the predicted trend of suction stress with matric suction (described as suction stress characteristic curves, SSCC) for the specimen of sand under the $p_{n}$ of $70 \mathrm{kPa}$ during hydraulic hysteresis. $\alpha$ and $n$ were obtained by fitting the van Genuchten SWRC model to the experimental curve presented in Figure 4(b) $(\alpha=0.18$ and $n=8.1)$. A comparison of the trend in $p_{s}$ with the measured values of $G_{\max }$ indicated that $G_{\max }$ of the sandy specimen followed an up and down trend during hydraulic hysteresis complying with the shape of SSCC.

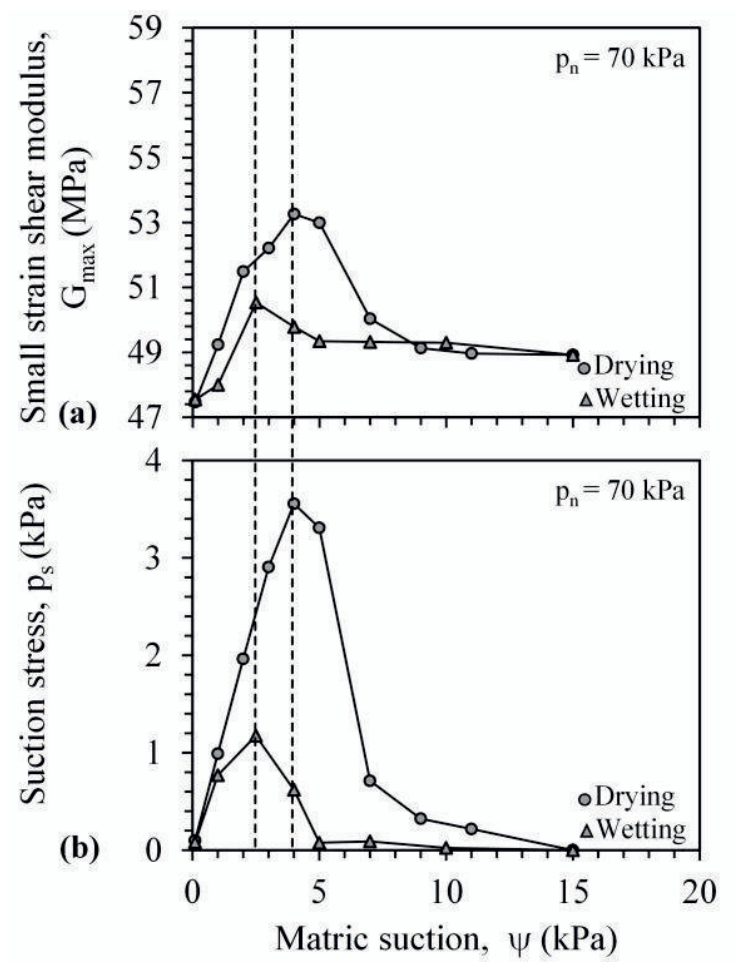

Figure 7. Hysteretic behavior during drainage and imbibition for silica sand specimens at mean net stress of $70 \mathrm{kPa}$ : (a) $G_{\max }$; (b) SSCC 
Based on the results presented in Figure 7(b), the SSCC followed an initial increase with matric suction, reaching a maximum value at a suction corresponding to the maximum small strain shear modulus. When increasing suction beyond this specific value, the suction stress values dropped nonlinearly to a magnitude of zero at a suction stress of $15 \mathrm{kPa}$. During imbibition, similar to the experimental $G_{\max }$ data, a hysteresis behavior in $p_{s}$ was observed, with values of suction stress being lower than those during drainage. The predicted SSCC is consistent with those reported by [14].

\section{Conclusion}

In the current study, variations in the small strain shear modulus during hydraulic hysteresis were investigated for specimens of silt and sand. The combination of matric suction control using the axis translation technique and shear wave velocity measurement using a pair of bender elements housed in the bottom platen and top cap of the setup allowed the measurements of the small strain shear modulus along different cycles of drainage and imbibition.

According to the results of this study, different trends for $G_{\max }$ were observed during hydraulic hysteresis in the case of unsaturated silt and sand. Based on the performed analysis, hardening of soil caused by drainage played a key role in the dynamic response of unsaturated silty soils at small strains, with $G_{\max }$ and $p_{c}{ }^{\prime}$ having similar evolving trends during hydraulic hystersis. While the well-known continuous increasing trend for $G_{\max }$ of silt with matric suction, $G_{\max }$ of sand varied in an up and down manner with respect to matric suction; a behaviour complying with the shape of the suction stress characteristic curve, SSCC.

\section{References}

1. C.W.W. Ng, J. Xu, S.Y. Yung, Can. Geotech. J., 46(9), 1062-1076 (2009)

2. A. Khosravi, J.S. McCartney, ASCE J. Geotech. and Geoenviron. Eng. 138(11), 1326-1333 (2012)

3. K.S. Wong, D. Masin, C.W.W. Ng, J. Comput. Geotech., 56, 28-39 (2014)

4. A. Khosravi, A. Gheibi, M. Rahimi, J.S. McCartney, S.M. Haeri, The 15th Asian Regional Conference on Soil Mechanics, 15ARC (Fukuoka, Japan, 2015)

5. X. Qian, D.H. Gray, R.D. Woods, Geotech. Test. J. 14(3), 266-275 (1991)

6. A. Khosravi, M. Ghayoomi, J.S. McCartney, H.Y. Ko, Geo-Florida 2010: Advances in Analysis, Modeling \& Design, (West Palm Beach, FL, 2010)

7. M. Ghayoomi, J.S. McCartney, Geotech. Test. J. 34(5), 1-11 (2011)

8. M. Asslan, F. Wuttke, Unsaturated Soils: Research and Applications, Springer Link, PP. 355-362 (2012)
9. W.T. Oh, S.K. Vanapalli, Geotech. Geol. Eng. 32(2), 259-271 (2014)

10. J.W. Hilf, Technical Memorandum No. 654, United State Department of the Interior Bureau of Reclamation, Design and Construction Division, Denver, Colorado, USA (1956)

11. A. Sawangsuriya, T.B. Edil, P.J. Bosscher, J. Geotech. Geoenviron. Eng. 132(2), 131-142 (2009)

12. Y. Dong, N. Lu, J.S. McCartney, J. Geotech. Geoenviron. Eng. (2015)

13. N. Lu, W.J. Likos, J. Geotech. Geoenviron. Eng. 132(2), 131-142 (2006)

14. N. Lu, T. H. Kim, S. Sture, W. J. Likos, J. Eng. Mech. 135(12), 1410-1419 (2009)

15. S. Oh, N. Lu, Vadose Zone J. 13(5) (2014).

16. N. Lu, J. W. Godt, D. T. Wu, Water Resour. Res. 46.5. (2010) 